\title{
The Supervision Impact towards Medical Learning in Experimentation Evolution through the Clinical Knowledge and Skills Application
}

\author{
Nor Shela binti Saleh \\ Hashim Fauzy bin Yaacob \\ Faculty of Management, Malaysian University of Technology, Malaysia \\ shela_saleh87@yahoo.com.my; hfauzy@utm.my
}

\section{Doi:10.5901/mjss.2015.v6n1p459}

\section{Abstract}

This research conducted at Hospital Pakar Sultanah Fatimah, Johor. The purpose of this research is identifying the level of clinical skill and trainee doctor achievement in medical learning experimentation. Besides that, researcher will identify either the clinical supervision as a moderator or non-moderator. The data collected shown the researcher getting 98 of questionnaire returned. The researcher have been done do pilot study and the alpha cronbach finding is high. Next, the researcher analyse output through descriptive statistics (mean, frequency and percentage) and inferential statistic (pearson correlation and hierarchical regression. The output shown the level of clinical skills and knowledge used and the achievement of experimentation learning is high. The correlation analysis shown there are low positive correlation between clinical skills use with experimentation learning achievement. However, based on output the relationship is not influences by the supervision clinical moderator. The output shown the first hypothesis is accepted and second hypothesis was rejected.

Keywords: Supervision; Clinical Skills and Knowledge; Experimentation Learning Achievement; Trainee Doctor; Housemanship

\section{Introduction}

Housemanship learning also calls as medical graduate learning process. The housemanship is compulsory program by trainee doctor before they recognized as the professional medical practitioners in Malaysian Medical Council. Period of housemanship programs is two until four years as maximum. The Malaysian Ministry of Health optimism the product is enabling to end the housemanship program within two years. In addition, the quality of trainee doctor confidence accomplished the standard in Malaysian Medical Council.

The realize quality achievement is challenging to reached. The detecting process from the executive of ministry in higher education cooperate with Malaysian Medical Council continuously achievement recognizing as frequent in order to identify the level of trainee doctor from the foundation. All the accomplishment is winning for identify and perceive towards the quality of curriculum provide by university. The detecting at overseas university also inclines in identifying action. Among the involve university is Indonesian, Indian, Russian, United Kingdom, United States, Germany, Egypt, Australian, Taiwan, Ukraine, Jordan, Saudi Arabic, New Zealand, Pakistan, Myanmar and Bangladesh. The purpose of action at universities as the commencement of act to guarantee zero factors enables to depress the medical learning reputation. The detection occur because establish the problem among trainee doctor reappearance from overseas and allocation in Malaysian. The main phenomenon exists related with experimentation learning while in housemanship.

Importance of achievement in experimentation learning support facilitating by the supervision. The supervision is guiding the trainee doctor find the greatest approach for experimentation learning. Vidal and John (2007) mention about the supervision having ability to identify the trainee doctor level of competence. Furthermore, the Malaysian Medical Council have been done introduce "A Guidebook for House Officers" regarding the medical learning process involved the supervision intervention. Besides, the development of competency unit correspondingly identifying the quality of trainee doctor achievement (Salam et al., 2008). The quality of trainee doctor depends on the contribution of experimentation. Clearly, the patient is a main person those impacted from the medical experimentation achievement (Ratzan, 2010). The supervisor enable avoid the risk, an accident and problem through guidance from them (Zachariae et al. 2003; Matheson \& Matheson, 2009; Piette et al. 2005).

The importance while in housemanship always takes as serious problem if the achievement is lowest. Many action and effort is taken from The Medical Ministry of Country as the paradigm movement to build the trainee doctor charismatic in order to pessimism in learning process. The effort is not only concerning the housemanship objective but 
too achieve the competence doctor complementary in term of quality and quantity (Bender, Bruce \& Rand, 2004). Furthermore, impact miscarried in experimentation learning reasons numerous may be the side effects such as an operation treatment, patient checking and others involved experimentation learning process (Hombergh, Wit \& Balen, 2009). For example, there are many case reported regarding the trainee doctor unsuccessfully achieve the experimentation standardized and fail to achieve the procedure while in housemanship. The unsuccessful in experimentation process as a patient limitation to get the good health. The probability the unsuccessfully impact the patient condition, illness and the successful of treatment (Matheson \& Matheson, 2009; Mc Gill, van der Vleuten \& Clarke, 2011). The supervisor should be as a guidance to simplify the trainee doctor duties at workplace in case patient treatment process.

Many action, campaign and course are taken from time to time. The shown government really concern to citizen for allocation the good health services. Even, Malaysian citizen knows the importance of health care for accomplished the great performance in career. According to Norman, van der Vleuten and Newble (2002), organization only needs and approximating a good employee of health. Moreover, human capital develops skill by good condition of employee body like a physical and free from mental problem. Consequently, the Ministry of Health in Malaysia needs a lot of trainee doctor excellent in job performance, competencies, the leadership dynamic in duty, readiness to challenging job and task necessity to be completed (Ahmad \& Ramsay, 2009). Therefore, trainee doctor need to produce and shape their cognitive and highest intellectual concept in order to help them reached the standardized quality necessary while in housemanship teaching (Palmer \& Naccarato, 2007).

\section{Literature Review}

\subsection{The Clinical Skill and Knowledge while in Housemanship}

According to Malling et al. (2009), the clinical skill and knowledge is present capacity and proficiency in task implementation practice whichever fixes in laboratory or at hospital. Generally, the clinical skill focuses on the skill attainment throughout at medical school or university of medic application (Celebi et al. 2012; Sommanson \& Trell, 1996). Thus, the clinical skill and knowledge used need to practice in frequency application. Furthermore, the Ministry of Health allusion among the factor trainee doctor failure while in housemanship arises from the poor of clinical skill and knowledge practice. The university or medical school prerequisite to identify and analyse the syllabus a long of medical course implement. The several reason the importance of medical skill necessity to complete. The greatest practice might be effect patient's sicknesses and perchance enable to revolution several mechanism (Celebi et al., 2012; Simpson \& Long, 2007). The various hospital received the trainee doctor from others country. Based on survey, a lot of issues generate when a trainee doctor failure to do basic of patient check-up has. Among the basic check-up such as the modest body medical check-up, blood pressure check-up, the blood sugar check-up and others.

The failure of clinical use affects the trainee doctor job performance in order to effect the housemanship learning achievement. Thus, the clinical skills need to apply with the appropriate technique. Following the ethic, procedure and rule support trainee doctor too successfully in experimentation task (Collins, 2009; Vos, 2009). Furthermore, working process could be in systematic and strategic in learning. The systematic may as a reason once to supervision help the trainee doctor such as supervisor (Weiss et al. 2005). The knowledge and experience beginning of supervisor could be practice and monitor the trainee doctor to organize task in comprehensive. Refer to Pulcini et al. (2013), he found in one hospital at United Kingdom, a group of trainee doctor do the task without supervisor guidance. At the end of the task, they create the extensive period occupied to complete the task but still incomplete. Later, a group of trainee doctor encounter with their supervisor and discuss the task difficult. The supervisor does evaluation and gives the assumption. The supervisor found there are numerous limitation and problem. The implementation not follows the right procedure. The supervisor similarly found something lost on that task implementation. Hence, with know-how the supervisor does correction and renovates the task complete by trainee doctor. It's clearly that the supervisor role as change agent to confirm the task qualify to manage and recondition. The experience of supervisor make a group of trainee doctor avoid misguided and surplus time and budget.

The trainee doctor also needs knowledge for housemanship preparation. Clinical knowledge function to implement the trainee doctor preparation and to complete an idea occurs for duties ended. According to Donnon, Paolucciu and Violato (2007), knowledge and skill possibly will be polish and as a founder to advance an idea and skill from trainee doctos. The appropriate knowledge of skills needs to complex with environment and current issues in order to increase the widening of knowledge skills completed. The weakness of reason of intellectual might be effect the contribution of knowledge skill in the direction of experimentation. Even though, Carr (2009) debate the knowledge importance is logic 
and suitable with highest achievement of thinking in medical education.

The statement need to knowledge practice in experimentation learning in medical. Shulruf et al. (2012) indication the knowledge submission in experimentation needed to apply and precarious intelligent for practice it. Trainee doctor needs to improve the critical and creativity of knowledge. Implementation of critical and creativity would be for done approximately innovative in experimentation. The creativity and critical of knowledge application conceivably develop new of experimentation. The fresh and ideas need for transformation and innovation in experimentation learning process. Constructed on James, Yates and Nicholson (2010); O'Neill et al. (2011) proclamation, in medical experimentation the influence of knowledge greatest importance intended for trainee doctor performance and patient contribution. The patient wants the superlative of treatment and elucidation for some of illnesses. The treatment besides requirement the judiciously and integrities in experimentation ended. The while be occupied too prerequisite shortly but unspoiled in experimentation.

Accordingly, trainee doctor must to apply the greatest of knowledge and skill of clinical while in housemanship experimentation learning. The amalgamation of knowledge and skill as a capital for subsidize the necessary in experimentation. The experimentation learning needs knowledge skill for generate a philosophies and expertise for completed and variety it as confidence equal essence. The trainee doctor prerequisite toughly in both the essential for efficacious and extraordinary achievement whereas in experimentation. The prominence one is escape incorrect and hazard as long as in housemanship of learning progression.

\subsection{The Experimentation of Learning while in Housemanship}

Experimentation learning involved practical, thinking, learning by doing and learning by creating an ideas concept. Besides that, experimentation learning also involved the action, mind and behaviour in learning activity (Malling et al., 2009; Weiner et al., 2001 and Beauchamp, 2005). Accordingly to Kolb (1984), experimentation is a one of learning phase in Kolb Learning Cycle 1984. In Kolb learning theory, experimentation derived from an experience, observation and conceptual develop to implement in learning. Significance that, Kolb learning theory elaborate the cycle of learning whereby the four learning style continuousness among every side. Every single of learning phases impact another phases in cycle. However, from the four of learning phases, researcher only highlight on experimentation as like in objective and focus of this study. The selected reason by the highlight and opinion from Ponzer et al. (2004), indication experimentation is the importance in medical learning specifically housemanship currently process. Scheffer et al. (2009); Schmeichel, and Baumeister (2004), similarly provision the declaration with simple conclusion that is the competencies of trainee doctor evaluate by the effectiveness in experimentation and the job completed (Diemes et al., 2011). Actually, the principle calls as learning by doing of trainee doctor while in housemanship (Malling et al., 2009).

Experimentation of learning correlated with clinical knowledge and skills. Weak of skill and knowledge uses affect the lowest experimentation achievement (Rogers et al., 2003). There are many similarities of clinical skill and knowledge and experimentation learning (Crisp, 2010). For example skill and knowledge practice in experimentation learning such as patient checks-up, patient treatment and training some medicine to patient. Several researchers call it as simulation (Ellaway, 2011). The simulation process elaborates the adaptation of clinical skill and knowledge to generate in experimentation. For example, in one of case in hospital happen at Sweden. The case conducted by Wanggren, Petterssonand Gemzell-Danielsson (2011). Based on the case, researchers have 10 trainee doctors. The researcher separated the trainee doctor in two groups by five people in every small group. Researcher renames the group with group A and group B. Group A practice the skill and knowledge. Group B only practice all an experience in housemanship currently for implement task. The output receiving, group A more capability because they facilitate responsibility task in little period, perfect job and capable.

According Urlings-Strop (2009), involvement wanted a while as experimentation learning. The highest achievement in experimentation activate with dynamic involvement (Boelen \& Woolard, 2009). However, Walsh (2010) judgement concerning to accomplished the experimentation, two importance entity is required. The first is quality and second is quantity. Harmonizing in quality necessity is equivalent with number of quantity. The balancing of quality and quantity in experimentation learning efficiency showed the upright development (Razack et al., 2013; Razack et al., 2012). One of accomplishment to comprehend the quality and quantity is clinical supervision tactics (Ezziane, 2012; Whitehead et al., 2012). The clinical supervision conducts by supervisor have experience and knowledge in medical education. The supervisor talented evaluates the trainee doctor presentation and providing remark or suggestion if any problem occurs in housemanship currently of learning (Barry \& Bia 2006; Bligh 2004).

The role of supervisor monitor trainee doctor follows the housemanship procedure and regulation in experimentation learning. Furthermore, Malaysian country serious and aware with procedure of medical is learning. The 
importance of procedure following avoid several accident happen and as safety first (Kumar, 2011). There are smaller of trainee doctor in certain cases not follow the housemanship learning ethic, procedure until receiving serious accident. Alike at United States case, 44000 patient die because the misguided of trainee doctor during patient experimentation (Bartlett et al., 2008). Besides that, the rule following make the learning process more in discipline, systematic and effective (Hoff, Pohl \& Bartfield, 2004; Cassar, 2004). Furthermore, the trainee doctor always absorb by medical learning experts and supervisor at workplace.

According to Branessa (2013) at one of hospital in United States, she found 700 trainee doctor practices their clinical skill and knowledge for emergency cases. Emergency cases and traumatic matter need a good clinical skill and knowledge. Trainee doctor necessity to select the importance treatment for save patient from coma. In emergency department, numerous cases there and trainee doctor extra responsibility the practice than thinking because the matter occurs in unexpectedly (Brunt et al., 2008; Naylor et al., 2010). An accident, fever, cancer and many more type of sickness occur in emergency of department. Occasionally, traumatic patient also happen suddenly and the trainee doctor should know the importance things proceeds action by stage. The chronology of systematic experimentation practice requirement perfect and trainee doctor needs avoid the faulty or slowly in treatment practise and thinking. Besides, department of emergency received various background of patient such as children, old people, adult, and perhaps new born babies. The clinical skill and knowledge necessities additional time management need to practice for encouragement the best treatment in the department for save all patients.

Researcher establishes there are numerous cases and concerns regarding the risk and accident contribute by trainee doctor at hospital while in housemanship learning. According to Illing (2008), the major problematic occurs since certain of trainee doctor unsuccessful to pay attention and monitor supervisor instructions in learning demonstration. The implication such as affect the trainee doctor learning achievement and negative side reasons the trainee doctor infection or particular accidental problem. For example, according to Tromski- Klingshirn (2006), the trainee doctor refuse to follow supervisor instructions impact their private health. The impact occur involve 50000 of trainee doctor. The cases reported at one of hospital at United States since year of 2006. All cases showed the trainee doctors receiving virus in blood infection. Similarity in Naing, Zulkifli and Ismail (1995) cases found the number of trainee doctor receiving blood infection since 4354 person. Besides that, other cases reported alike two cases before such as 119 from 1022 of trainee doctor getting blood toxic waste infection since year of 1990 until 1996 (Osborn, Papadakis \& Gerberding, 1999). Koenig and Chua (1995) also found there are 48 per cent of trainee doctor at Washington expose in blood infection. Based on the cases conclusion, supervision and supervisor contribute something to trainee doctor in medical education. The supervisor as guidance and the supervision as the controller program to build and develop skill and knowledge of trainee doctor learning by doing, learning by thinking contribution in housemanship.

\section{The Clinical Supervision while in Housemanship Learning}

According to Cate and Durning (2007), the clinical supervision occur in hospital supervision among the senior or experts to trainee doctor while in housemanship. As normally supervisor is select based on the period of services, the level of knowledge, contribution and experience. Supervision is a process to guide, too simplified, to conversation information about learning while in housemanship. Thus, the supervision to accomplish the housemanship currently of learning needs. The Ministry of Health permanently takings action and top approaches to comprehend the nature supervision while in housemanship requests.

The supervision involved several of learning activity (Bambling et al., 2006). Hand-on activity under supervision and professionals' importance one. The experts select through certificate in Ministry of Health in country. The experts or supervisor needs to guide the trainee doctor following the syllabus in House Officer Guidance Book. The book mentions others supervision objective and mission as below:

i. To introduce and explain the organisation and department background in hospital.

ii. To explain the organisation and department Standard Operating Procedure (SOP).

iii. To list and clearly in details the trainee doctor task and responsibility while in housemanship.

iv. To explain the assumption and perception of department and organisation regarding housemanship currently of learning.'

v. To provide an overview the task specification and rotation placement of trainee doctor in ward.

vi. Become a mentor, referee and counsellor of trainee doctor current impasse in discharging its duties.

vii. Verification procedures carried out in the Log Book

viii. Act as a guide during the placement of trainee's doctor.

ix. Provide performance reports of trainee doctor supervised and produce a variety of trainee doctor performance 
coach.

Based on the duties listed, researcher found the supervision importance to become a moderator between the clinical skill and knowledge use with the experimentation learning relationship. Ardnt et al. (2007) support the statement and comment that supervisor is the superlative person to monitor trainee doctor while in housemanship learning. Occasionally, trainee doctor feel relaxed get a guide from others peer or senior while in housemanship. The action of trainee doctor to get guide from peer or senior it's not good because the colleagues still on-going the housemanship and uncompleted yet. So, trainee doctor take benefits from supervisor guidance. The supervisor needs to alert and awake their role on order to polish and develop the trainee doctor skill and knowledge and experimentation achievement (Hilton \& Slotnick, 2005). Sharing knowledge and giving ideas and sharing the positive experience a phase to construct the confident level of trainee doctor clinical skill and knowledge practises (Bensing et al., 2006 \& Lisa, 2001). Even though, a poor of skill and knowledge from supervisor exposed the low of sharing experience among trainee doctor and supervisor (Berwick, 2003; Barnett et al., 2007; Goldacre, Taylor \& Lambert, 2010).

Sometimes, the supervision contributes negative side to trainee doctors. Conflict as natural the main cause the negative side existed among supervisor and trainee doctor. For example in one incident, the conflict occurs among trainee doctor and their supervisor as while as making patient brain details check-up. According to supervisor assumption, the patient is normal and not a cancer (Benign). The supervisor suggests giving simple medicine to the patient. Even though, the trainee doctor suggests doing a Computer Tomography (CT scan) or Magnetic Resonance Imaging (MRI) to check details and instil. Nevertheless the supervisor disagrees. Then the last treatment, both supervisor and trainee doctor found the patient have sicknesses in Lymphatic Tissue and (Blood Vessel). Good communication and explanation needs from two people to safe the patient condition in beginning check-up.

Even though the supervision is compulsory in medical education, for long time supervision is an essential. Nielsen et al. (2012) and Kuper et al. (2007) statement the trainee doctor capability and discipline later the housemanship needed. If while in housemanship the trainee doctor always refers to their supervision, conceivably the confidence level as a decision maker is trouble. The trainee doctor needs to explore their potential and polish by personal. Several approaches may take it for trainee doctor develop skills. The suit way is reading and attends talk or medical learning ceremony. From time to time, the skill and knowledge make perfect and build successfully until in the upcoming career.

\section{Research Hypothesis}

Researcher determination two hypotheses; the first hypothesis is relationship between clinical skill and knowledge users with the learning achievement experimentation. The second hypothesis is the clinical supervision as moderator among the clinical skill and knowledge user with the learning achievement experimentation relationship.

Ha1: There is a relationship between the trainee doctor clinical skill and knowledge uses with experimentation achievement learning while in housemanship.

$\mathrm{Ha2}$ : There is a influences of clinical supervision towards the trainee doctor clinical skill and knowledge uses with experimentation achievement learning while in housemanship relationship.

\section{Research Objective}

(1) To identify level of trainee doctor clinical skill and knowledge used while in housemanship.

(2) To identify level of trainee doctor learning experimentation while in housemanship.

(3) To investigate the relationship among clinical skill and knowledge used with learning experimentation achievement of trainee doctor while in housemanship.

(4) To investigate either the supervision clinical as a moderator towards clinical skill and knowledge used with experimentation learning achievement of trainee doctor while in housemanship.

\section{Research Methodology}

The research has been completed conducted at Hospital Sultanah Pakar Fatimah Muar, Johor, Malaysia. The hospital also equipped with technologies in materials treatment. The hospital is as teaching hospital and expert's hospital in Johor, Malaysia. Scope of study was selected the second year of trainee doctors. 108 number of trainee doctor as research population. The simple random sampling procedures in this research for target the respondents. From 108 number of questionnaire distribute, 98 is returned. The comparison of number of questionnaire percentage distributes and returned since 90.74 per cent. The questionnaire develops by researcher through adaptation from others journal and previous 
research. Among the previous research selected is about the medical learning, experimentation learning, clinical skills and theory of learning (O' Busari et al., 2005; Spence et al., 2002; Spence et al., 2002; Kolb 1984). The set of questionnaire measure through Likert Scale (Hair et al., 1998). Afterward, for the validity test confirmation have been done with experts in research fields. On purpose validity test confirm the element and the research questionnaire appropriate and measurable (Gravetter 2009; Elmes et al., 2006). The validity does by experts whereby the excellent and experiences professor and associate professor in learning and medical education from other research universities of Malaysian. In addition, the reliability test also been done for strongly the validity test. The pilot test had been done for acquire the Alpha Cronbach value. Pilot test purpose to warrant the strongly and accurate like in Table 1 (Sekaran, 2003). Based on finding in pilot test, researcher gets the good and excellent value $(0.805$ until 0.903$)$.

Table 1. Alpha Cronbach Values in Pilot Test Finding

\begin{tabular}{|l|c|}
\hline Element & Alpha Cronbach \\
\hline Clinical and Knowledge Skill used & 0.805 \\
Experimentation Learning Achievement & 0.854 \\
Clinical Supervision & 0.903 \\
\hline
\end{tabular}

Subsequently the pilot test, the researcher analyses to complete the research objective. Descriptive method had been done to analyses the first and second objective. Likewise, the hypothesis tested, third and fourth objective complete through inferential analysis. The Figure 2 illuminate the research framework clarify the independence variables, dependence variable and moderator variable.

As a conclusion from the research methodology, researcher found that the method for data sampling is simple random sampling is most appropriate. The purpose because, probability complete a lot of sample is highest than other sampling method. Besides, all target respondents have potential selected as sample in data sampling. Approximately the reliability test, researcher select the pilot test because to see the value of alpha cronbach. The pilot test help researcher confident with the item and element of strength. Besides that, researcher also practices the validity test. The validity test has been done by expert those select. The function of this technique to confirm the item is precise suitable and appropriate to select in item or elements of study. Amongst the validity expert chosen is associate professor and professor level from Research University in Malaysian. The impact from the research methodology enables the accurate and strength of data finding is empirical.

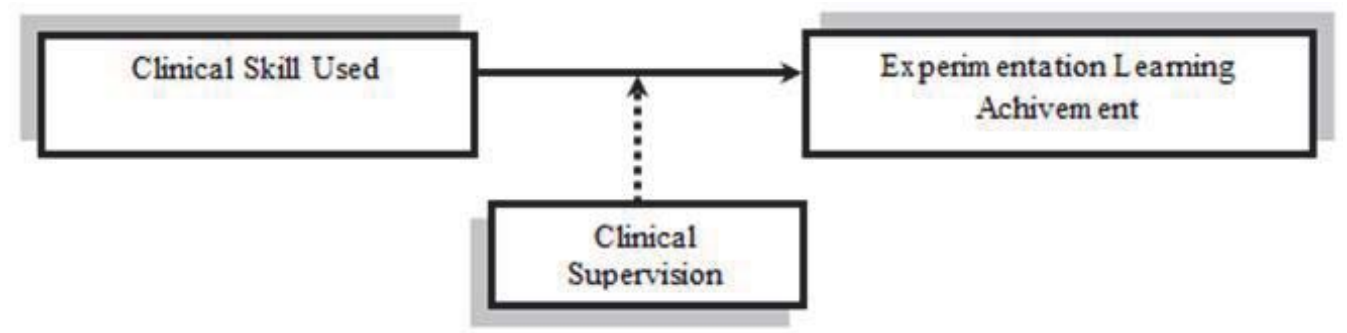

Figure 1. Research Framework 


\section{Research Finding}

\subsection{Background of Respondents}

Table 2. Respondents Background

\begin{tabular}{|c|c|c|}
\hline Background & \multicolumn{2}{|c|}{$\begin{array}{c}\text { Frequency (f) Percentage (\%) } \\
\qquad(\mathrm{n}=98)\end{array}$} \\
\hline $\begin{array}{l}\text { Gender } \\
\text { Male } \\
\text { Female }\end{array}$ & $\begin{array}{l}34 \\
64\end{array}$ & $\begin{array}{l}34.7 \\
65.3\end{array}$ \\
\hline $\begin{array}{c}\text { Age } \\
25 \text { years old } \\
26 \text { years old } \\
27 \text { years old } \\
28 \text { years old } \\
30 \text { years old } \\
31 \text { years old }\end{array}$ & $\begin{array}{c}36 \\
38 \\
10 \\
7 \\
4 \\
3\end{array}$ & $\begin{array}{c}36.73 \\
38.78 \\
10.20 \\
7.14 \\
4.08 \\
3.06\end{array}$ \\
\hline $\begin{array}{l}\text { Race } \\
\text { Malay } \\
\text { China } \\
\text { Indian } \\
\text { Others }\end{array}$ & $\begin{array}{c}79 \\
15 \\
4 \\
0\end{array}$ & $\begin{array}{c}80.6 \\
15.3 \\
4.1 \\
0\end{array}$ \\
\hline
\end{tabular}

Refer on table 2, the finding discussion about respondents' particulars. There are 98 number of respondents expected in this research. The female respondents more than male was 30 people. The male respondent was collected 34 people (34.7\%), whereby the female collected 64 people (65.3\%). Refer to level of age finding, there are 4 of respondents age is 30,3 respondents is 31 years old. Further, the majority respondents age is 26 years old (38 respondents), the second highest of age value is 25 years old ( 36 respondents) and third is 27 years old (10 respondents). Finally, for the 28 years old only collected 7 of respondent. Others analysis in background of respondents is race. Majority respondents are Malay $(80.60 \%)$, second the highest number category of race is China (15.30\%) and the lowest value of race is Indian (4.1\%). For the others race, zero of number has been noted.

\subsection{The Level of Skill and Knowledge Clinical Used of Trainee Doctor while in Housemanship}

Refer on table 3 has been shown the level of clinical skills and knowledge of trainee doctor used. The finding has been shown 89.80 per cent (88 respondents) having the highest of level in clinical skill used. Only 10 respondents (10.20\%) having the moderate level. Zero of respondents having the lowest of level in clinical skill uses. Mean value is 3.95, the standard deviation is 0.28 . The maximum value is 4.83 , while the minimum value is 3.17 .

Table 3. Level of Clinical of Knowledge and Skill Used

\begin{tabular}{|c|c|c|c|c|c|c|}
\hline Level & $\begin{array}{c}\text { Frequency (f) } \\
(\mathrm{n}=98)\end{array}$ & Percentage (\%) & Mean & Standard Deviation & Minimum Value & Maximum Value \\
\hline Highest & 88 & 89.80 & \multirow{3}{*}{3.95} & \multirow{3}{*}{0.28} & \multirow{3}{*}{3.17} & \multirow{3}{*}{4.83} \\
\hline Moderate & 10 & 10.20 & & & & \\
\hline Lowest & 0 & 0 & & & & \\
\hline
\end{tabular}

\subsection{The Level of Experimentation Learning Achievement while In Housemanship}

Refer on table 4 has been shown the level of experimentation learning achievement of trainee doctors. From 98 of respondents, zero of numbers get the lowest level in experimentation learning achievement. Only highest and moderate found in this part analysis. A number 76 (77.55\%), has highest level and only $22.45 \%$ (22 respondents) has moderate level. The maximum and minimum value in this finding had shown 5.00 and 2.83. Standard deviation value is 0.60 , while the mean is 4.00 . 
Table 4. Level of experimentation of learning achievement

\begin{tabular}{|l|c|c|c|c|c|c|}
\hline Level & $\begin{array}{c}\text { Frequency }(\boldsymbol{f}) \\
(\mathbf{n}=98)\end{array}$ & Percentage (\%) & Mean & Standard Deviation & Minimum Value & Maximum Value \\
\hline Highest & 76 & 77.55 & \multirow{2}{*}{4.00} & 0.60 & 2.83 & 5.00 \\
\cline { 1 - 3 } Moderate & 22 & 22.45 & 4.0 & & & \\
\hline Lowest & 0 & 0 & & & & \\
\hline
\end{tabular}

\subsection{The Relationship between Clinical Skill Used with Experimentation Learning Achievement}

Refer on table 5, presented the finding of correlation between clinical skill usages with experimentation learning achievement. There is relationship among both correlation analyses. The strongly of correlation is lowest is value $r=$ 0.318. The significance value performs based on the $p$ value not as much of the level significance of study. The level of significance of study is 0.001 and the finding shown $p=0.000$. Refer in finding, first hypothesis is accepted. The accepted of first hypothesis by means of there are relationship between clinical skill usages with experimentation learning achievement of trainee doctor in while housemanship learning. The accepted of hypothesis mark the nol hypotheses with rejected nol.

Table 5. Correlation Testing Among the Clinical Skill Used with Experimentation Learning Achievement

\begin{tabular}{|c|c|c|}
\hline Item & $r$ & Sig. \\
\hline Experimentation Learning & $0.318^{* *}$ & 0.000 \\
\hline
\end{tabular}

**Level of significance 0.01 (2-tailed)

The Supervision Clinical as a Moderator among Clinical Skill Used with Experimentation Learning Achievement of Trainee Doctor while in Housemanship

Referring on table 6 , the finding $\beta=-0.408, p=0.732$ has been showed highest value for supervision clinical as a moderator among clinical skill usage with experimentation learning achievement. Based on the finding, impervious there is no significance influenced by supervision clinical as a moderator in the relationship investigation. The finding rejected second hypothesis. The value of variance also showed the lowest one that is 0.001 . This research rejected the hypothesis approximately there are influenced of supervision clinical among clinical skill usage with experimentation learning achievement of trainee doctor while in housemanship. The rejected of alternative hypothesis mark the nol hypothesis is accepted.

Table 6. The Supervision Clinical as a Moderator Among Clinical Skill Used with Experimentation Learning Achievement Findings

\begin{tabular}{|l|c|c|c|c|}
\hline \multirow{2}{*}{ Step of Finding } & \multicolumn{4}{|c|}{ Experimentation Learning Achievement } \\
\cline { 2 - 5 } & $\mathrm{R}^{2}$ & $\Delta \mathrm{R}^{2}$ & $\beta$ & Sig. \\
\hline $\begin{array}{l}\text { Step 1: Independence Variable } \\
\text { Clinical Skill Usage }\end{array}$ & 0.101 & 0.101 & 0.318 & 0.001 \\
\hline $\begin{array}{l}\text { Step 2: Moderator Variable } \\
\text { Supervision Clinical }\end{array}$ & 0.376 & 0.275 & 0.532 & 0.000 \\
\hline $\begin{array}{l}\text { Step 3: Interaction Variable } \\
\text { Clinical Skill Usage x Clinical Supervision }\end{array}$ & 0.377 & 0.001 & -0.408 & 0.732 \\
\hline${ }^{*}<0.05, * * p<0.01$
\end{tabular}

\section{Discussion of Findings}

Figure 3 have been showed the research objectives finding was achieved. First objective has been showed the level of clinical skill usage of trainee doctor is highest with 3.95 value of mean. This finding has been showed the respondents practice highest clinical skills while in housemanship. This research similarly with Salam (2008) finding regarding the clinical skills likewise importance and practice in highest usage. Furthermore, the duties of trainee doctor continuously prerequisites the competence and strongly of clinical skill application while in housemanship learning (Ratzan 2011). Amongst the competence of trainee doctor successful practice clinical skill such as the ability to complete duties, follow 
the instructions and procedures, ethic job as long a performance and qualified job outcome (Vidal \& John 2007; Teunissen \& Westerman 2009).

The second research objective also achieved highest level of mean (4.00). Second objective establish the trainee doctor receiving highest in experimentation learning achievement while in housemanship. Findings proof the trainee doctor as research respondents perform and capability to complete their task and duties. The findings also supported by others previous of research. According to previous of research, philosopher and theorist of medical field declaration, if the trainee doctor allow achieved the highest in experimentation learning, this is superlative in medical practitioners (Hombergh, Wit \& Balen 2009; Matheson \& Matheson 2009; McGill, van der Vleuten \& Clarken 2011).

Referring on the third research objective, first hypothesis accepted. The accepted of hypothesis for there are relationship among clinical skill usage with experimentation of learning achievement. The findings only shown lowest of correlation value $\left(r=0.318^{\star *}\right)$, however it's still under significance. The conclusion of third objective explained that the highest of clinical skill usage to affect the highest of experimentation learning achievement. In contrast, the lowest of clinical skill usage value affect the lowest of experimentation learning achievement. The statement of findings has been supported by Wood (2009) and Dobie 2007. Both of them mention the competencies of trainee doctor will be measures as competence and dedication the clinical uses is frequent and systematic usage practices. Scheffer et al. 2009 mention is the clinical skills importance as a founder, basis of knowledge and need to practice in experimentation

The fourth objective has been showed the rejected of second hypothesis. The rejected second hypothesis because the supervision clinical not influenced the clinical skill usage and experimentation of learning achievement while in housemanship learning. Meaning that, the clinical supervision appears, but not impact either positive or negative implication towards the research relationship. This finding debate Ahmad and Ramsay (2009) is supervisor as a controller the trainee doctor activity while in housemanship. Conceivably, the bias supervision occurred while in housemanship only was stress, conflict and demotivated a number of of trainee doctor (Palmer \& Naccarato, 2007). Certain of supervisor only focus on some doctor such as same gender or background of race. Consequently, the not impact by supervision clinical strongly this finding and reject the second of research objective formed.

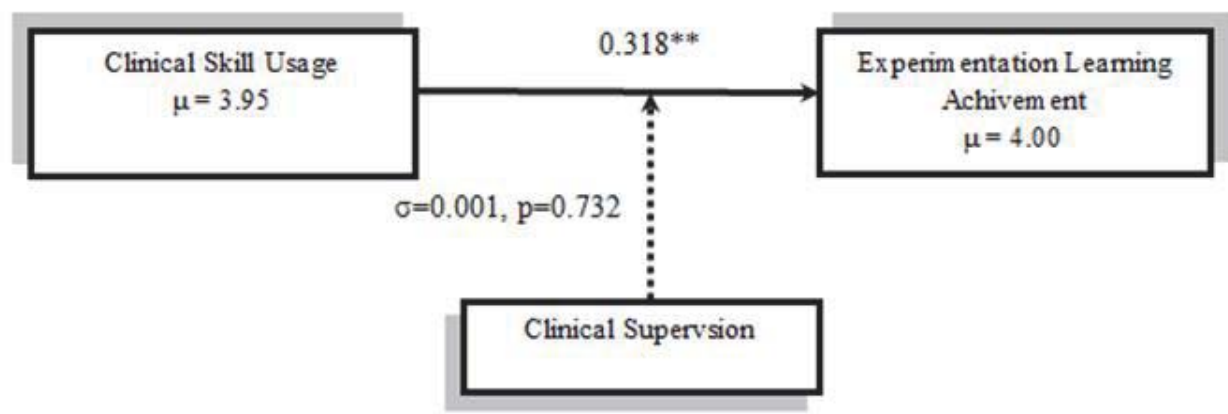

\section{Conclusion}

Medical field as a basic and foundation impact the health, intellectual and active in community. Consequently, the enhancement of clinical skill should be achieved in order to occur the excellent and competence of trainee doctor. The excellent in duties such as complete the entire requirement while in housemanship, achieve strongly job performance and higher in quality and quantity output be finished. The maximum determination and stage of expand the medical learning desired from time to time till the upcoming of generation like paradigm movement services. Moreover, medical education needs to implement new idea, and innovation involvement. An innovation ideas like a modern technology approaches in medical experimentation and learning trial appropriate reputation. The new reformation of mind and behaviour of transformation be achieved from the body of health and active thinking. All the reformation and transformation optimism sustain the health community, active of society in order to produce top of level thinking in human capital equipped.

\section{References}

Ahmad, K. \& Ramsay, B. (2009). Analysis of Inpatient Dermatologic Referrals: Insight Into the Educational Needs of Trainee Doctors. Journal of Medical Sciences. 17(8), 69-71.

Ardnt, U., Behrens, F., Ziswiler, H., Kaltwasser, J. \& Moller, B. (2007). Observational Study of a Patient and Doctor Directed Pre-Referral Questionnaire for an Early Arthritis Clinic. Journal of Medical Education, 42(2), 763-768. 
Aukes, L. A., Geertsma, J., Choen-Schotanus, J., Swierstra, R. P., \& Slaets, J. P. J. (2007). The Development of a Scale to Measure Personal Reflection in Medical Practice and Education. Journal of Medical Teaching, 29 (5), 177-182.

Bambling, M., King, R., Raue, P., Schweither, R., \& Lambert, W. (2006). Medical Supervision: Supervision Profession in Training Programme for the Helping Education. Journal of Medical Supervision, 16(6), 55-78.

Barnett, M. M., Fisher, J. D., Cooke, H., James, P. R. \& Dale, J. (2007). Breaking Bad News: Consultants' Experience, Previous Education and Views on Educational Format and Timing. Journal of Medical Education, 41 (2), 947-956.

Barry, M. \& Bia, F. J. (2006). Department of Medicine and International Health. American Journal of Medicine, 80(6), 19-21.

Bartlett, G., Blais, R., Tamblyn, R., Clermont, R. J., \& MacGibbon, B. 2008. Impact of Patient Communication Problems on the Risk of Preventable Adverse Events in Acute Care Settings. Canadian Medical Association Journal, 178(12), 1555-1562.

Beauchamp, R. D. (2005). The Changing Roles of a Surgical Department Chair: Adapting to a Changing Environment. Journal of Surgery and Medical, 140(100), 258-263.

Bender, R., Bruce, G. \& Rand, C. 2004. Medication Non-Adherence and Asthma Treatment Cost. Journal of Allergy and Clinical Immunology, 4 (3), 191-195.

Bensing, J. M., Tromp, F., van Dulmen, S., van den Brink-Muinen, A., Verheul, W., \& Schellevis, F. G. (2006). Shifts in Doctor-Patient Communication Between 1986 And 2002: A Study of Videotaped General Practice Consultations with Hypertension Patients. Journal of Medical Family Practice, 7 (6), 62-65.

Berwick, D. M. (2003). Disseminating Innovations in Health Care. Journal of Medical and Health Care, 289(12), 1969-1975.

Bligh, J. (2004). More Medical Students, More Stress in the Medical Education System. Journal of Medical Education, 38(1), 460-462.

Boelen, C. \& Woollard, B. (2009). Social Accountability and Accreditation: a New Frontier for Educational Institutions. Journal of Medical Education. 43(9): 887-894.

Brenessa, M., Lindeman, M. D. A., Pamela, A., Lipsett, M. D., Adnan, A., Anne, O. \& Lidor, K. (2013). Medical Student Subinternships in Surgery: Characterization and Needs Assessment. The American Journal of Surgery, 205(54), 175-181.

Brunt, L. M., Halpin, V. J. \& Klingensmith, M. E. (2008). Advanced Skills Preparation and Assessment for Senior Medical Students Entering Surgical Internship. Journal of Surgery and Medical, 206(102), 897-907.

Cassar, K. (2004). Development of an Instrument to Measure the Surgical Operating Theatre Learning Environment as Perceived by Basic Surgical Trainees. Journal of Medical Teaching, 26(18), 260-264.

Cate, O. T. \& Durning, S. (2007). Peer Teaching in Medical Education: Twelve Reasons to Move from Theory to Practice. Journal of Medical Education, 29(7), 591 - 599.

Celebi, N., Tsouraki, R., Engel, C., Holderried, F., Riessen, R. \& Weyrich, P. (2012). Does Doctors' Workload Impact Supervision and Ward Activities of Final-Year Students: A Prospective Study. Journal of Medical Education, 12 (3), 24-32.

Collins, J. (2009). Challenges and Opportunities in the Scholarship of Discovery. Journal of Medical Education, 14(2), 169-185.

Crisp, N. (2010). Turning the World Upside Down - The Search for Global Health in the 21st Century. Oxford University Press: New York.

Diemers, A. D., Margje, W. J., van de Wiel, Albert, J. J., Scherpbier, A., Erik, H., Diana, H., \& Dolmans, J. (2011). Pre-Clinical Patient Contacts and the Application of Biomedical and Clinical Knowledge. Journal of Medical Education, 45(17), 280-288.

Dobie, S. (2007). Self-Awareness, Mindful Practice and Relationship-Centred Care as Foundations for Medical Education. Journal of Academic Medicine, 82(4), 422-427.

Ellaway, R. (2011). E-Learning: Is the Revolution Over. Journal of Medical Teaching, 33(1), 297-302.

Eskander, A., Shandling, M. \& Hanson, M. D. (2013). Should the Exam be Used for Medical School Admissions in Canada. Academic Medicine: Journal of the Association of American Medical Colleges, 88(5), 572-580.

Ezziane, Z. (2012). The Important of Clinical Leadership in Twenty-First Century Health Care. International Journal of Health Promotion and Education, 50(5), 261-269.

Foldevi, M., Sommanson, G. \& Trell, E. (1996). Problem-Based Medical Education General Practice and Health Care Quality Assurance. International Journal of Health Care Quality Assurance, 9(1),5-14.

Foster, K. (2011). Becoming a Professional Doctor. Journal of Medical Education, 16(9), 10-17.

Frank, J. R. \& Snell, L. S.( 2010). For the International CBME Collaborators: A New Vision of Competency-Based Medical Education and Definition of Competence. The 14th Ottawa Conference on Assessment of Competence in Medicine and the Healthcare Professions at 18 May 2010. Miami: Amerika Syarikat.

Goldacre, M. J., Taylor, K. \& Lambert J. (2010). Views of Junior Doctors About Whether their Medical School Prepared them Well for Work: Questionnaire Surveys. Journal of Medical Education, 10(78), 1-9.

Hilton, S. R. \& Slotnick, H. B. (2005). Proto-Professionalism: How Profession Occurs Across the Continuum of Medical Education. Journal of Medical Education, 39(4), 58-65.

Hoff, T. J., Pohl, H. dan Bartfield, J. (2004). Creating a Learning Environment to Produce Competent Residents: The Roles of Culture and Context. Journal of Academic Medicine, 79(55), 532-539.

Hombergh, P. V. D., Wit, N. J. \& Balen, F. A. (2009). Experience as a Doctor in the Developing World: Does it Benefit the Clinical and Organizational Performance in General Practice. Journal of Family Practice and Health, 10(3), 80-90.

Illing, J., Peile, E. \& Morrison, J. (2008). How Prepared are Medical Graduates to Begin Practice: a Comparison of Three Diverse UK Medical Schools. Final Report for the GMC Education Committee. General Medical Centre 2008: London.

Kelly, P. A., Haidet, P., Schneider, V., Searle, N., Seidel, C. L. \& Richards, B. F. (2002). A Comparison of in-Class Learner Engagement Across Lecture, Problem-Based Learning, and Team Learning Using the Strobe Classroom Observation Tool. Teaching and 
Learning in Medicine: an International Journal, 17(2), 112-118.

Koenig, S. \& Chu, J. (1995). Medical Student Exposure to Blood and Infectious Body Fluids. American Journal of Infection Control, 23(1), 40-43.

Kolb, D. A. (1984). Experiental Learning : Experiences as a Source of Learning and Development. New Jersey: Prentice Hall.

Kron, F. W., Gjerde, C. L. Sen, A. \& Fetters, M. (2010). Medical Students Attitudes Towards Video Games and Related New Media Technologies in Medical Education. Journal of Medical Education, 10(4), 50-69.

Kuper, A., Reeves, S., Albert, M. \& Hodges, B. D. (2007). Assessment: do we Need to Broaden our Methodological Horizons. Journal of Medical Education, 41(5), 1121-1123.

Lamout, S. M., Alias, N.A. \& Win, M. N. (2003). Red Flag in Patient Presenting with Headache: Clinical Indications for Neuromaging. British Journal of Radioliology, 76 (90), 532-535.

Leinster, S. (2011). Evaluation and Assessment of Social Accountability in Medical Schools. Journal of Medical Teacher, 33(8), 673676.

Lindblom, P., Scheja, M., Torell, E., Astrand, P. \& Fellander-Tsai, L. (2007). Learning Orthopaedics: Assessing Medical Students' Experiences of Interprofessional Training in an Orthopaedic Clinical Education Ward. Journal of Interprofessional Care, 21(2), $413-423$.

Lisa, M. D. (2001). Brain Tumors. Brain Journal, 344(15), 114-123.

Malling, B., Bonderup, T., Mortensen, L., Ringsted, C. \& Scherpbier, A. (2009). Effects of Multi-Source Feedback on Developmental Plans for Leaders of Postgraduate Medical Education. Journal of Medical Education, 43(29), 159-167.

Matheson, C. \& Matheson, D. (2009). How Well Prepared are Medical Students for their First Year as Doctors; the Views of Consultants and Specialist Registrars in Two Teaching Hospitals. Postgraduate Medical Journal, 85(1009), 582-589.

Maudsley, G. \& Strivens, J. (2001). Promoting Professional Knowledge, Experiential Learning and Critical Thinking for Medical Students. Discussion Papers: Journal of Medical Education, 43(4), 535-544.

McGill, D. A., van der Vleuten, C. P. \& Clarke, M. J. (2011). Supervisor Assessment of Clinical and Professional Competence of Medical Trainees: A Realibility Study Using Workplace Data and a Focused Analytical Literature Review. Journal of Health Sciences and Education, 16(1), 405-425.

Molapo, M. \& Muula, A. S. (2010). Perspectives of Patients Towards Medical Students at the Queen Elizabeth Central. Journal of Health Research, 12(7), 85-93.

Naing, N. N., Zulkifli Ahmad \& Ismail Kamaruzzaman (1995). Needle-Stick Injuries in Medical Students. Malaysian Journal of Medical Sciences, 2(1), 59-61.

Naylor, R. A., Hollett, L. A. \& Castellvi, A. (2010). Preparing Medical Students to Enter Surgery Residencies. American Journal of Surgery, 99(19), 105-109.

Nielsen, G. H. M., Skjerve, J., Jacobsen, C. H., Gullestad, S. E., Hansen, B. R., Reishelt, S., Ronnested, M. H. \& Torgersen, A. M. (2012). Mutual Assumption and Facts about Nondisclosure among Clinical Supervisors and Students in Group Supervision: a Comparative Analysis. Journal of Nordic Psychology, 61(4), 49-58.

Norman, G. R., van der Vleuten, C. P. M. \& Newble, D. I. (2002). International Handbook of Research in Medical Education. Dordrecht: Kluwer Academic Publishers.

Osborn, E. H., Papadakis, M. A. \& Gerberding, J. L. 1999. Occupational Exposures to Body Fluid in Medical Students. A Seven Year Longitudinal Study. International Medicine Journal, 130(1), 45-51.

Palmer, C. \& Naccarato, N. 2007. Differences in Radiation Therapy Staff and Students' Perceptions of Clinical Teaching Characteristics. Journal of Radiotherapy in Practice, 6(2), 93-102.

Piette, J. D., Heisler, M., Krein, S. \& Kerr, E. A. 2005. The Role of Patientphysician Trust in Moderating Medication Nonadherence Due to Cost Pressures. Archives of Internal Medicine of Journal, 165(73), 1749-1755.

Ponzer, S., Hylin, U., Kusoffsky, A., Lauffs, M., Lonka, K., Mattiasson, A. C. \& Nordstrom, G. 2004. Inter Professional Training in the Context of Clinical Practice: Goals and Students' Perceptions on Clinical Education Wards. Journal of Medical Education, 38(15), $727-736$.

Pulcini, F., Williams, N., Molinari, P., Davey, Y. \& D. Nathwani. 2013. Junior Doctors' Knowledge and Perceptions of Antibiotic Resistance and Prescribing: a Survey in France and Scotland. Journal of Clinical Mocrobiology, 17(18), 80-87.

Ratzan, S. (2010). Moving from IEC to IHC - The Time is Now. Journal of Health Communication, 15(7), 691-694.

Razack, S., Lessard, D., D. Hodges, B., H. Maguire, M. \& Steinert, Y. (2013). The More it Changes; the More it Remains the Same: a Foucauldian Analysis of Canadian Policy Documents Relevant to Student Selection for Medical School. Journal of Advanced in Health Science Education, 12(7), 17-27.

Razack, S., Maguire, M., Hodges, B. \& Steinert, Y. (2012). What Might we be Saying to Potential Applicants to Medical School; Discourses of Excellence, Equity, and Diversity on the Web Sites of Canada. Journal of Academic Medicine, 87(10), 1-7.

Rogers, A., Day, J., Randall, F. \& Bentall, R. P. (2003). Patients Understanding and Participation in a Trial Designed to Improve the Management of Anti-Psychotic Medication: a Qualitative Study. Journal of Social Psychiatry Psychiatric Epidemiology, 38(13), 720-727.

Salam, A., Mohd Perdaus, A. F., Md Isa, S. H., Zainuddin, Z., Latiff, A. A., Pheng, N. S., Yusuf, Z., Soelaiman, I. N., Mohamad, N. \& Moktar, N. (2008). UKM Medical Graduates' Perception of their Communication Skills During Housemanship. Journal of Medical and Health, 3(1), 54-58.

Scheffer, C., Tauschel, D., Cysarz, D., Hahn, L., Ngler, A. \& Riechmann, M. (2009). Learning by Active Participation in Clinical Care- A 
Feasibility Study of a Clinical Education Ward in Internal Medicine. Journal of Medical Australian, 26(3), 31-47.

Schmeichel, B. J. \& Baumeister, R. F. (2004). Self-Regulatory Strength. Dalam R. F. Baumeister \& K. D. Vohs: Handbook of SelfRegulation: Research, Theory, and Applications. (Edt.). (ms. 84-98). The Guilford Press: New York.

Simpson, S. A. \& Long, J. A. (2007). Medical Students-Run Health Clinics: Important Contributirs to Patient Care and Medical Education. Journal of Medical Education, 27(9), 25-27.

Skjerve, J., Nielsen, G. H., Jacobsen, C. H., Gullestad, S. E., Hansen, B. R., Reichelt, S. Ronnested, M. H. \& Torgersen, A. M. (2009). The Supervisor Perspective Towards Supervisee. Journal of Supervision, 61(4), $28-48$.

Steinert, Y. (2010). Faculty Development in the New Millennium: Key Changes and Future Directions. Journal of Medical \& Teaching, 22(1), 7-13.

Teunissen, P. W. \& Westerman, M. (2011). Opportunity or Threat: The Ambiguity of the Consequences of Transitions in Medical Education. Journal of Medical Education, 45(1), 51-59.

Tromski-Klingshirn, D. (2006). Should the Clinical Supervisor be the Administrative Supervisor. The Clinical Supervisor of Journal, 25(12), 53-67.

Urlings-Strop, L. C. (2009). Selection of Medical Students: a Controlled Experiment. Journal of Medical Education, 21(43), 175-183.

Vidal, F. P. \& John, N. W. (2007). Principles and Applications of Compute Graphics in Medicine. Journal of Medical Education, 51(4), 166-175.

Voellinger, R., Taffe, P., Cornuz, J., Durieux, P. \& Burnand, B. (2011). Discriminant Validity and Test-Retest Reliability of a SelfAdministered Internet-Based Questionnaire Testing Doctors' Knowledge in Evidence-Based Medicine. Journal of Evaluation in Clinical Practice, 17(21), 471-477.

Vos, M. (2009). Communication Quality and Added Value: a Measurement Instrument for Municipalities. Journal of Communication Management, 13(4), 362-377.

Walsh, K. (2010). Cost Effectiveness in Medical Education. Oxford: Radcliffe Publishing Ltd.

Wanggren, K., Pettersson, G. \& Gemzell-Danielsson, H. (2010). Medical Students Learning the Pelvic Examination: Evaluation of a Clinical Patient Model. Journal of Obstetric and Gyncology, 89(27), 1304-1309.

Weiner, B. J., Culbertson, R., Jones, R. F. \& Dickler, R. (2001). Organizational Models for Medical School-Clinical Enterprise Relationships. Journal of Academic Medicine, 76(42), 113-124.

Weiss, P. M., Kollwer, C. A., Hess, L. W. \& Wasser,T. (2005). How do Medical Student Self-Assessments Compare with their Final Clerkship Grades. Journal of Medical Teaching, 27(5), 445-449.

White, C. B. (2007). Smoothing out Transitions: How Pedagogy Influences Medical Students' Achievement of Self-Regulated Learning Goals. Advances in Health Sciences Education, 12(7), 279-297.

Whitehead, C.R., Hodges, B.D., \& Austin, Z. (2012). Captive On A Carousel: Discourses of 'New' In Medical Education 1910-1920. Advance in Health Science Education, 17(4), 4-8.

Wood, T. (2009). Assessment not Only Drives Learning, it May Also Help Learning. Journal of Medical Education, 43(1), 5-6.

Young, M. E., Razack, S., Hanson, M. D., Slade, S., Varpio, L., Dore, K.L. \& Mckight, D. (2012). Calling for a Broader Conceptualization of Diversity: Surface and Deep Diversity in Four Canadian Medical Schools. Journal Academic Medicine, 87(11), 1501-1510.

Yudkowsky, R., Otaki, J., Lowenstein, T., Riddle, J., Nishigori, H. \& Bordage, G. (2009). A Hypothesis-Driven Physical Examination Learning and Assessment Procedure for Medical Students: Initial Validity Evidence. Journal of Medical Education, 43(17), 729740.

Zachariae, R., Pedersen, C. G., Jensen, A. B., Ehrnrooth, E., Rossen, P. B. \& von der Maase, H. (2003). Association of Perceived Physician Communication Style with Patient Satisfaction Distress, Centre-Related Self-Efficacy, and Perceived Control Over the Disease. British Journal of Cancer, 88(5), 65-68.

Ziegelstein, R. C. \& Fiebach, N. H. (2004). The Mirror and the Village: a New Method for Teaching Practice-Based Learning and Improvement and Systems-Based Practice. Journal of Academic Medicine, 79(13), 83-88. 